\title{
Age-hardening by grain interior and grain boundary precipitation in an Au-Ag-Pt-Zn-In alloy for multipurpose dental use
}

\author{
Joo-Hee Park, Mi-Hyang Cho, Mi-Gyoung Parka, Yong Hoon Kwon, \\ Hyung-II Kim and Hyo-Joung Seol \\ www.goldbulletin.org
}

\begin{abstract}
The complex precipitation mechanisms related to the age-hardening of Cu-free Au-Ag-Pt-Zn-In alloy for multipurpose dental use was studied by means of hardness test, X-ray diffraction (XRD) studies, field emission scanning electron microscopic (FE-SEM) observations, energy dispersive spectrometer (EDS) analysis, and electron probe microanalysis (EPMA). The early diffusion and then clustering of the In-concentrated phase in the grain interior, together with the early diffusion and then ordering of the $\mathrm{PtZn}$ phase in the grain boundary, introduced the internal strains in the Au-Ag-rich $\alpha_{1}$ matrix, resulting in the hardening process. As the Au-Ag-rich $\alpha_{1}{ }^{\prime}$ and PtZn $\beta$ lamellarforming grain boundary reaction progressed, the phase boundaries between the solute-depleted face-centered cubic (FCC) $\alpha_{1}^{\prime}$ matrix and the face-centered tetragonal (FCT) PtZn $\beta$ precipitate reduced, resulting in softening. In the particlelike structures composed of the major Pt-Au-rich $\alpha_{2}$ phase and the minor Pt-Zn-rich $\alpha_{3}$ phase, the separation of $\mathrm{In}$ and $\mathrm{Zn}$ progressed producing the In-increased Pt-Au-rich $\alpha_{2}^{\prime}$ phase and the
\end{abstract}

Department of Dental Materials, School of Dentistry and Medical Research Institute, Pusan National University,

Beomeo-Ri, Mulgeum-Eup, Yangsan-Si,

Gyeongsangnam-Do, 626-814, South Korea

a Department of Dental Lab. Science, College of Health Sciences, Catholic University of Pusan, \#9, Bugok 3-dong, Geumjeong-gu, Busan, 609-757, South Korea

* Corresponding author: Hyo-Joung Seol

Tel: 82-51-510-8229, Fax: 82-51-510-8228,

E-mail:seol222@pusan.ac.kr

Keywords: precipitation, lamellar-forming grain boundary reaction, Au-Pt, Ag-Pt, Au-In, In-Zn
Zn-increased PtZn $\alpha_{3}^{\prime}$ phase with aging time without restraining the softening. The miscibility limit by complex systems of Au-Pt, Ag-Pt, Au-In and $I n-Z n$ resulted in the phase transformation and related microstructural changes.

\section{Introduction}

The majority of dental gold alloy is composed of an Au-Ag-Cu system with additives. The ternary Au$\mathrm{Ag}-\mathrm{Cu}$ system is characterized by decomposition regions into the Ag-rich and $\mathrm{Cu}$-rich regions and an AuCu ordering region. This chemical characterization is the result of $\mathrm{Ag}$ and $\mathrm{Cu}$ having limited miscibility, while $\mathrm{Au}$ is completely soluble with both $\mathrm{Ag}$ and $\mathrm{Cu}$ at any atomic ratio [1]. Thus, the hardening mechanism is usually attributed by dual mechanisms of phase separation into Ag-rich and $\mathrm{Cu}$-rich, and then ordering which forms the AuCu I ordered phase with a face-centered tetragonal (FCT) structure in the Cu-rich regions [2-6]. These types of dental gold alloys, the Au-Ag-Cu system cannot use as the basis of ceramic-metal restorations due to the relatively low melting temperature and a high thermal coefficient of expansion. In order to mitigate these problems, a relatively large amount of Pt was added to the basic dental gold alloy system, which allows the new dental gold alloy for multiple indications.

The multipurpose dental gold alloy composed of Cu-free Au-Ag-Pt-Zn-In was examined in this study. The major components, Au and Ag, have a miscibility limit with Pt in solid state, which can be seen in the binary phase diagrams of Au-Pt and Ag-Pt systems [1]. The minor ingredients, $I n$ and $Z n$, represent a simple eutectic in the assessed In-Zn binary phase diagram [1]. Thus, complex precipitation mechanisms were expected based on the present alloy composite. The hardening mechanism of the gold alloy for ceramic-metal restoration is known 
to be attributed to the ordered phases with a facecentered cubic (FCC) structure [7-10], and cannot be applied to gold alloy for multipurpose dental use, as the age-hardening mechanism and related phase transformation become different with a slight compositional change. The hardening mechanism of the gold alloy for multipurpose dental use has been studied rarely and, is not clear. The aim of the present study is to examine the complex precipitation mechanisms which are related to age-hardening in a Cu-free Au-Ag-Pt-Zn-In alloy for dental multipurpose, by characterizing the hardness changes and related phase transformation, microstructural, and element distributional changes during the aging process.

\section{Experimental details}

The alloy used in the present study was a multipurpose Au-Ag-Pt-Zn-In alloy (Aurium 55, Aurium research, U.S.A.). The chemical composition of the alloy is listed in Table 1. The initial shape of the specimen was plate-like with dimensions of $9 \mathrm{~mm} \times$ $9.5 \mathrm{~mm} \times 1 \mathrm{~mm}$, and was procured in a rolled and annealed state.

Table 1: Chemical composition of the alloy
\begin{tabular}{|lcccccccc|}
\hline Composition & Au & Ag & Pt & $\mathbf{Z n}$ & In & $\mathbf{P d}$ & $\begin{array}{c}\mathbf{R h} \\
\mathbf{+}+\text { Ta+lr) }\end{array}$ \\
\hline wt\% & 55 & 23 & 11.7 & 3 & 3.5 & 3 & 0.8 \\
\hline at\% & 42.0 & 32.1 & 9.0 & 6.9 & 4.6 & 4.2 & 1.2 \\
\hline
\end{tabular}

Prior to hardness testing, the specimens were solution-treated at $850^{\circ} \mathrm{C}$ for 15 min under an argon atmosphere, and then rapidly quenched into ice brine to preclude thermal changes on cooling. Specimens were subsequently aged isochronally for 10 and $20 \mathrm{~min}$ in a temperature range of $250^{\circ} \mathrm{C}$ to $600^{\circ} \mathrm{C}$, and were isothermally aged at $500^{\circ} \mathrm{C}$ for various periods of time. All aging was done in a molten salt bath, followed by quenching into ice brine. Hardness measurements were made using a Vickers micro-hardness tester (MVK-HI, Akashi Co., Japan) with a load of $300 \mathrm{gf}$ and a dwell time of $10 \mathrm{~s}$. Vickers hardness results were recorded as the average value of 5 measurements.

For the X-ray diffraction (XRD) studies, powder specimens which passed through a 300-mesh screen were obtained by filing the plate-like specimens. After being vacuum-sealed in a silica tube and solution- treated at $850^{\circ} \mathrm{C}$ for $15 \mathrm{~min}$, they were isothermally aged at $500^{\circ} \mathrm{C}$ for various period of time in a molten salt bath, and then quenched into ice brine. The $X$ ray diffraction profiles were recorded by an X-ray diffractometer (XPERT-PRO, Philips, Netherlands). The X-ray diffractometer was operated at $30 \mathrm{kV}$ and $40 \mathrm{~mA}$, using Ni-filtered $\mathrm{Cu} \mathrm{K} \alpha$ radiation and installed at Pusan National University.

For the field emission scanning electron microscopic (FE-SEM) observations, the plate-like specimens were subjected to the required heat treatment, and then they were prepared by utilizing standard metallographic techniques for FE-SEM examinations to observe the microstructural changes in the specimen alloy during the aging process. A freshly prepared aqueous solution composed of $10 \%$ potassium cyanide and $10 \%$ ammonium persulfate was utilized for the final etching of the samples. The specimens were examined at $20 \mathrm{kV}$ using a field emission scanning electron microscope (JSM6700F, JEOL, Japan) which was installed at Pukyong National University.

For the energy dispersive spectrometer (EDS) analysis and electron probe microanalysis (EPMA), the specimens were prepared as described above for the FE-SEM examinations. An energy dispersive XRay spectrometer (INCA x-sight, Oxford Instruments Ltd., UK) of an FE-SEM (JSM-6700F, JEOL, Japan) was used at $15 \mathrm{kV}$ for the EDS analysis and installed at Pukyong National University. And an electron probe X-ray microanalyser (EPMA-1600, Shimadzu, Japan) was used at $15 \mathrm{kV}$ for EPMA and installed at Pukyong National University.

\section{Results and discussion}

\subsection{Age-hardening behaviour}

To determine an appropriate aging temperature, the specimens were isochronally aged in the temperature range of $250^{\circ} \mathrm{C}$ to $600^{\circ} \mathrm{C}$. Fig. 1 shows the isochronal age-hardening curves of the specimen alloy solution-treated at $850^{\circ} \mathrm{C}$ for $15 \mathrm{~min}$, and then aged in the temperature range of $250^{\circ} \mathrm{C}$ to $600^{\circ} \mathrm{C}$ for 10 and $20 \mathrm{~min}$. The alloy exhibited an apparent age-hardenability at $500^{\circ} \mathrm{C}$. Thus, the agehardening behaviour with aging time was observed at $500^{\circ} \mathrm{C}$.

Fig. 2 shows the isothermal age-hardening curve of the alloy solution-treated at $850^{\circ} \mathrm{C}$ for $15 \mathrm{~min}$ and then aged for various periods of times at $500^{\circ} \mathrm{C}$. The hardness of the solution-treated specimen increased 


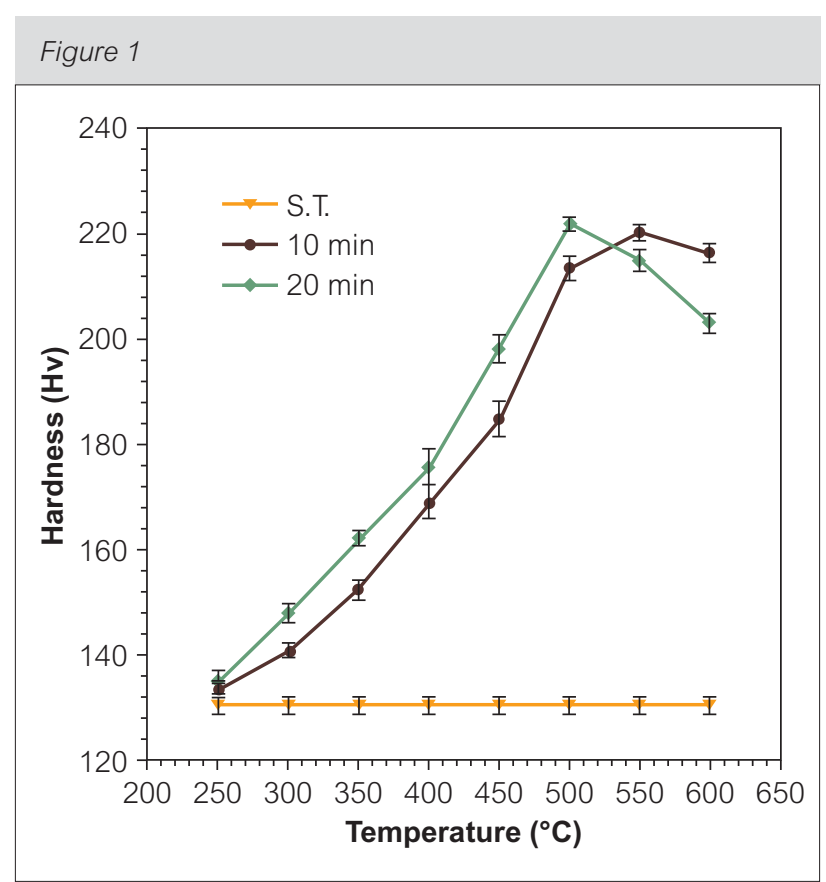

Isochronal age-hardening curves of the specimen alloy aged in the temperature range of $250^{\circ} \mathrm{C}$ to $600^{\circ} \mathrm{C}$ for $10 \mathrm{~min}$ and $20 \mathrm{~min}$

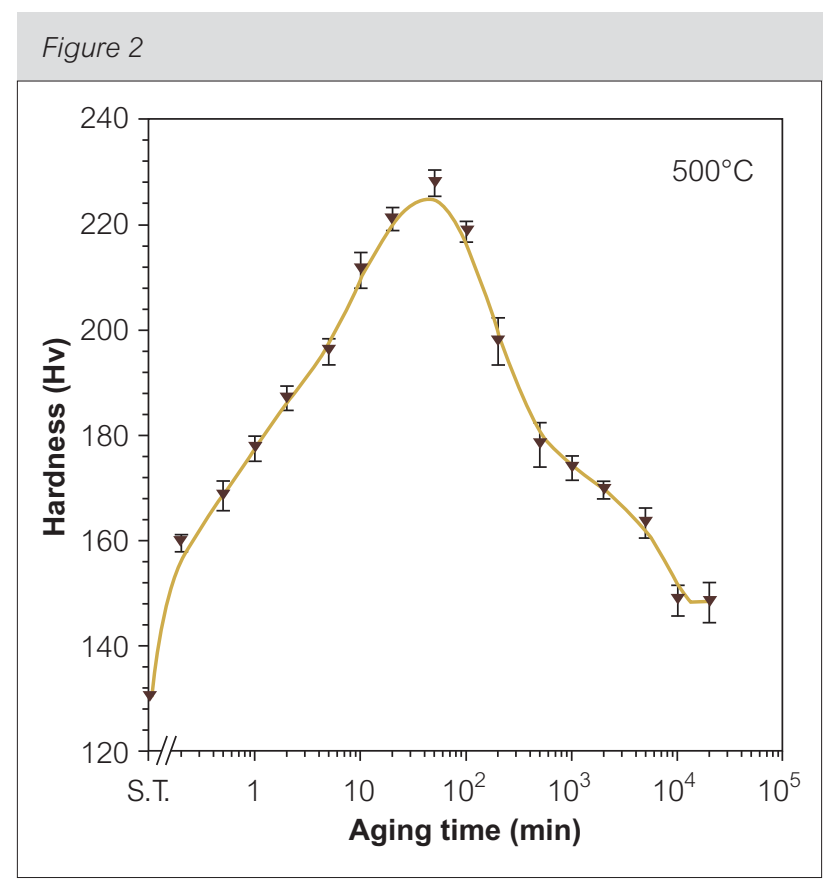

Isothermal age-hardening curve of the specimen alloy aged at $500^{\circ} \mathrm{C}$

rapidly and reached a maximum value at the aging time of $50 \mathrm{~min}$. Then the hardness decreased drastically, but near the aging time of 1,000 min, the decreasing rate of hardness slowed. Finally, the hardness stopped decreasing at the aging time of 10,000 min.

\subsection{Phase transformation}

Variations in the XRD pattern during isothermal aging were examined during isothermal aging at $500^{\circ} \mathrm{C}$ to clarify a relationship between the phase transformation and the hardness change during the aging process, which is demonstrated in Fig. 3. The XRD pattern of the solution-treated specimen showed 3 phases, $\alpha_{1}, \alpha_{2}$ and $\alpha_{3}$. The major $\alpha_{1}$ phase was AuAg-rich phase having a face-centered cubic (FCC) structure with a lattice parameter of $a_{200}=0.4064$ $\mathrm{nm}$. The $\alpha_{2}$ phase was Pt-Au-rich phase having an FCC structure with a lattice parameter of $a_{200}=0.3992$ $\mathrm{nm}$. The minor $\alpha_{3}$ phase was Pt-Zn-rich phase having an FCC structure with a lattice parameter of $a_{111}=0.3841 \mathrm{~nm}$.

By aging the solution-treated specimen at $500^{\circ} \mathrm{C}$ for 20,000 min, the Au-Ag-rich $\alpha_{1}$ phase was transformed into the Au-Ag-rich $\alpha_{1}^{\prime}$ phase with an increased lattice parameter, $a_{200}=0.4082 \mathrm{~nm}$ by precipitating the $\mathrm{PtZn}$ $\beta$ phase. The $\alpha_{2}$ and $\alpha_{3}$ phases were transformed

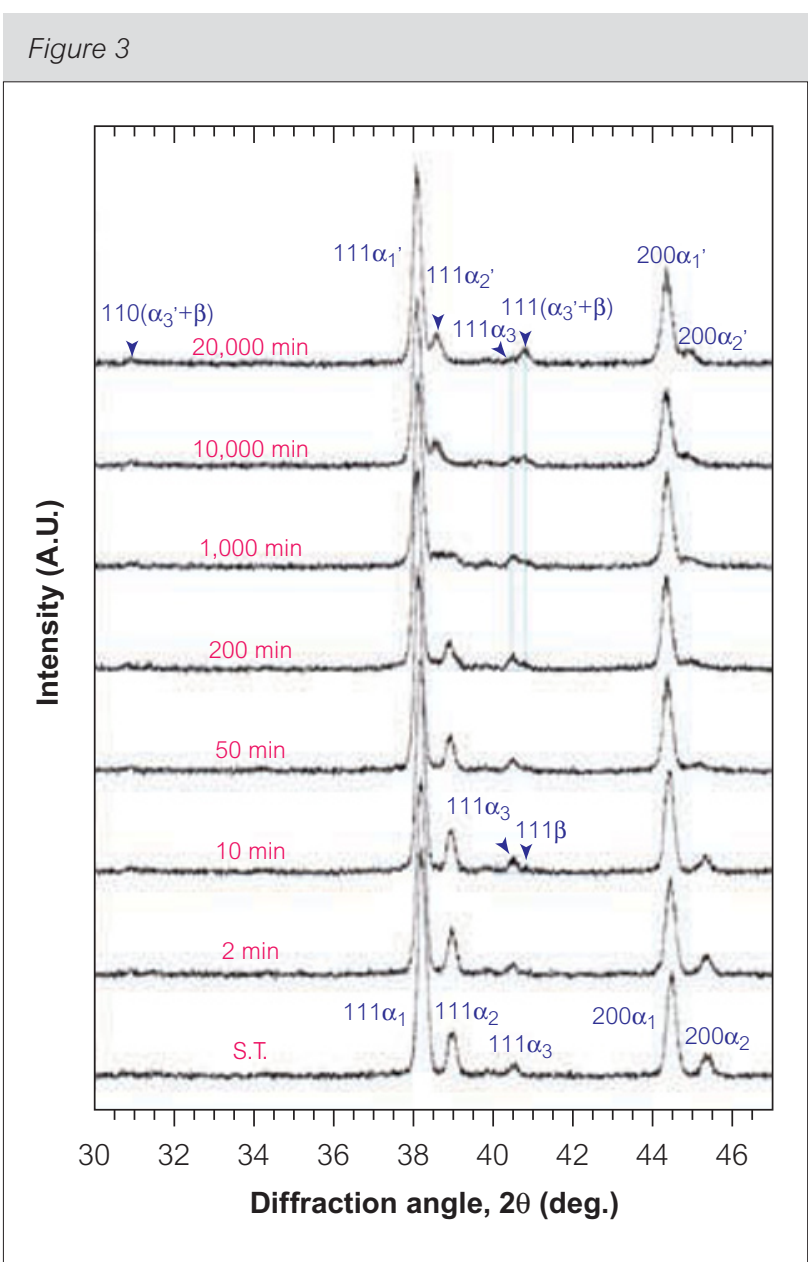

Variations of the XRD patterns during the isothermal aging at $500^{\circ} \mathrm{C}$ with aging time 
into the Pt-Au-In-rich $\alpha_{2}^{\prime}$ phase with an increased lattice parameter of $a_{111}=0.4034 \mathrm{~nm}$ and the PtZn $\alpha_{3}{ }^{\prime}$ phase with lattice parameters of $a_{110}=0.4076 \mathrm{~nm}$ and $c_{002}=0.3436 \mathrm{~nm}$, respectively [11]. Both the $\beta$ and $\alpha_{3}{ }^{\prime}$ phases were the same PtZn phase of AuCu I-type, but were named differently as they had originated from different phases and formed in different regions, as will be seen in the EDS analysis.

Changes in the XRD patterns during the isothermal aging at $500^{\circ} \mathrm{C}$ were examined with respect to the isothermal age hardening curve at $500^{\circ} \mathrm{C}$ (Fig. 2). At the aging time of $10 \mathrm{~min}$ when the hardness increased up to approximately $93 \%$ of its maximum value, the $\alpha_{1}$ peaks shifted a little toward lower diffraction angle side, and very weak $111 \beta$ peak appeared in the higher diffraction angle side of the $111 \alpha_{3}$ peak. Until the aging time of 50 min when the hardness increased up to the maximum value, the $200 \alpha_{2}$ peak became significantly broad. Therefore, the hardness increase during the early stages of the aging process was mainly related to the phase transformation of the $\alpha_{1}$ phase and secondarily to the $\alpha_{2}$ phase. By further aging until 1000 min when the decreasing rate in hardness slowed, the $\alpha_{2}$ phase transformation was apparent.

Further aging to 10,000 min when the hardness had decreased significantly from its maximum value, the transformation of the $111 \alpha_{2}$ peak into the $111 \alpha_{2}{ }^{\prime}$ peak almost finished, and concurrently the 111 peak intensity of the $\alpha_{3}$ phase decreased as that of the $\alpha_{3}$ ' phase increased. This resulted from the separation of $\mathrm{In}$ and $\mathrm{Zn}$ with aging time, as will be discussed in the EDS results. From the above, in the later stage of aging process, the phase transformation of $\alpha_{2}$ into $\alpha_{2}^{\prime}$ and $\alpha_{3}$ into $\alpha_{3}$ ' progressed, and which slowed the decreasing rate of hardness for a while. The phase transformation must have produced lattice strains resulting in hardening, as it was in various dental alloys [12-15]. However, it did not stop the softening process. Therefore, it was thought that some microstructural changes resulting in softening occurred during the later phase transformation.

\subsection{Microstructural changes}

FE-SEM observations were performed to clarify the microstructural changes that occurred during the hardness changes. Fig. 4 is showing the FE-SEM micrographs of 2,000X, 30,000X magnifications for the specimens solution-treated at $850^{\circ} \mathrm{C}$ for $15 \mathrm{~min}$ (A) and aged at $500^{\circ} \mathrm{C}$ for $50 \mathrm{~min}(\mathrm{~B}), 200 \mathrm{~min}(\mathrm{C})$, $10,000 \mathrm{~min}(\mathrm{D})$ and $20,000 \mathrm{~min}(\mathrm{E})$. In the FE-SEM micrograph of the solution-treated specimen $(A)$, matrix and particle-like structures were observed. From the alloy composition and the XRD peaks intensity, the matrix was the $\alpha_{1}$ phase being AuAg-rich, and the particle-like structures were the $\alpha_{2}$ phase being Pt-Au-rich and the $\alpha_{3}$ phase being PtZn-rich, as will be observed in the EDS results.
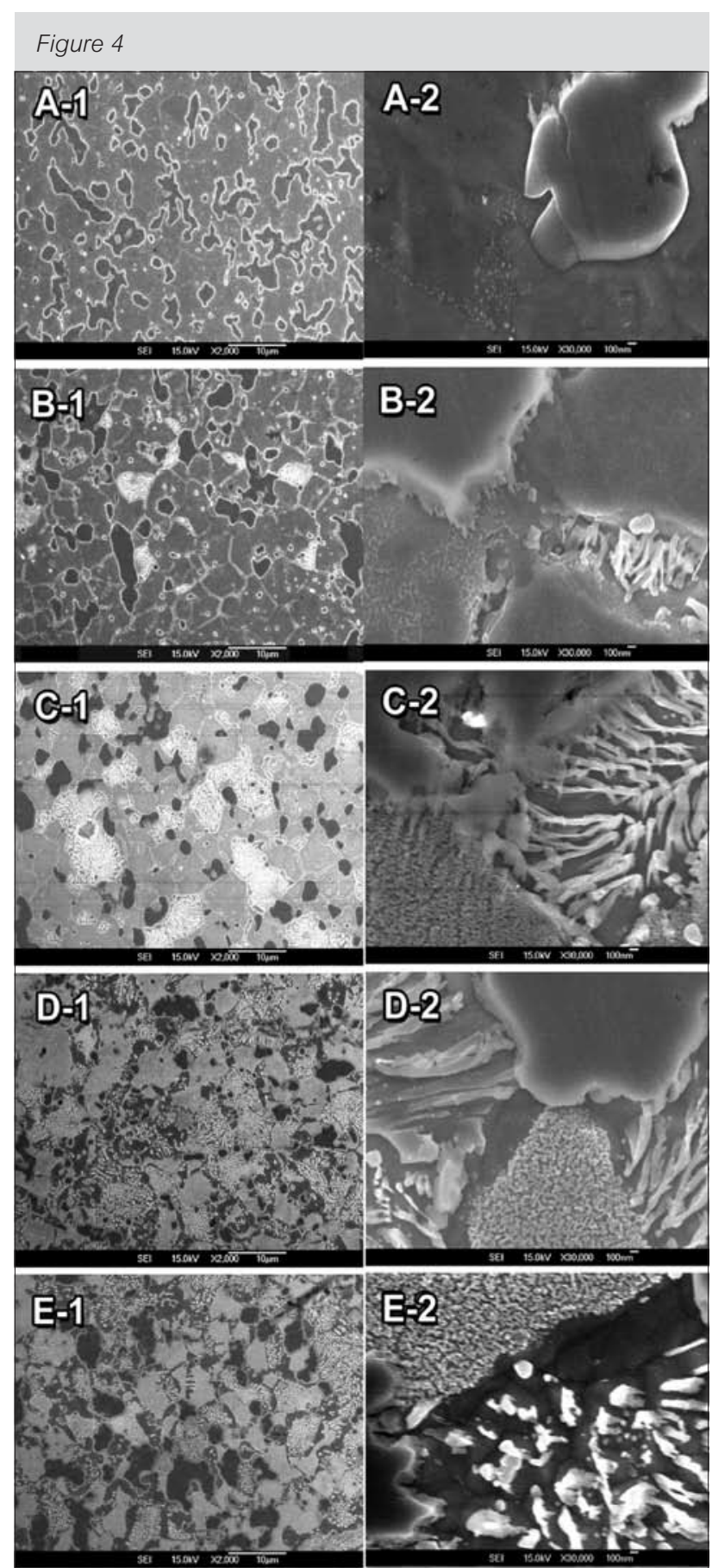

FE-SEM micrographs at magnifications of 2,000X (1) and $30,000 X$ (2) for the specimen solution-treated at $850^{\circ} \mathrm{C}$ for 15 $\mathrm{min}(A)$, and aged at $500^{\circ} \mathrm{C}$ for $50 \mathrm{~min}(B), 200 \mathrm{~min}(\mathrm{C}), 10,000$ $\min (D)$ and $20,000 \min (E)$ 
By aging the specimen at $500^{\circ} \mathrm{C}$ for $50 \mathrm{~min}(\mathrm{~B})$ when the maximum hardness value was obtained, fine lamellar structures formed in limited areas of the grain boundary. The appearance of lamellar structure stopped the further increase in hardness. In the corresponding XRD pattern, the PtZn $\beta$ peak began to appear as the main $\alpha_{1}$ peak shifted toward a lower diffraction angle. Thus, it was thought that the formation of lamellar structure resulted from the precipitation of the PtZn $\beta$ phase from the $\alpha_{1}$ matrix. By aging the specimen at $500^{\circ} \mathrm{C}$ for 200 min (C) when the hardness decreased to $87 \%$ of the maximum value, the grain boundary lamellar structure grew further into the grain interior, and the inter-lamellar spacing became broad. And fine, dotlike precipitates covered the grain interior except the particle-like structure, which was revealed to be the In-concentrated phase that diffused from the $\alpha_{1}$ phase, as will be discussed in the EDS results. It is thought that the microstructural changes occurred by the grain interior precipitation of the In-concentrated phase and the lamellar-forming grain boundary reaction by the PtZn phase.

By further aging the specimen for 10,000 min (D) when hardness had decreased to $65 \%$ of the maximum value, the volume fraction of the lamellar structure did not further increase. However, the inter-lamellar spacing broadened compared to the specimen that had been aged for $50 \mathrm{~min}$. The transformation of the $\alpha_{2}$ and $\alpha_{3}$ phases did not cause apparent microstructural changes in the particlelike structure. The further coarsening of the grain boundary lamellar structure did not occur by aging the specimen for 20,000 min (E), a point at which there was no further reduction in hardness.

From the above, it can be said that both the volume fraction of lamellar structure and the inter-lamellar spacing were proportional to the decreasing rate in hardness. It was thought that the early diffusion and then clustering of the In-concentrated phase in the grain interior together with the early diffusion and then ordering of the PtZn phase in the grain boundary introduced the internal strains in the matrix. But, as the microstructural coarsening, that is, mainly lamellar-forming grain boundary reaction progressed, the phase boundaries between the FCC matrix and the FCT PtZn precipitate reduced, and thus the internal strains released, resulting in softening $[6,16,17]$.

\subsection{Element distribution}

To identify the changes in element distribution produced by the aging process, the distribution of $\mathrm{Au}, \mathrm{Ag}, \mathrm{Pt}, \mathrm{Zn}, \mathrm{In}, \mathrm{Pd}$ was investigated by EDS analysis and EPMA. Fig. 5 shows the FE-SEM micrographs for the specimens solution-treated at $850^{\circ} \mathrm{C}$ for $15 \mathrm{~min}(\mathrm{~A})$ and aged at $500^{\circ} \mathrm{C}$ for 20,000 min (B). The element distribution in the matrix (M), particle-like structure $(P)$ and lamellar structure $(L)$ marked by an arrow was analyzed; the results are shown in Table 2(1,2), respectively. In the matrix (M)

\begin{tabular}{|c|c|c|c|c|c|c|}
\hline Region (at\%) & $\mathrm{Au}$ & $\mathrm{Ag}$ & $\mathrm{Pt}$ & $\mathrm{Zn}$ & In & $\mathbf{P d}$ \\
\hline$M(\alpha 1)$ & 51.4 & 36.7 & 1.2 & 3.7 & 3.3 & 3.7 \\
\hline P1 $(\alpha 2)$ & 27.5 & 4.6 & 29.7 & 11.2 & 14.7 & 12.3 \\
\hline P2 ( $\alpha 2)$ & 25.8 & 4.6 & 29.5 & 15.2 & 14.8 & 10.1 \\
\hline
\end{tabular}
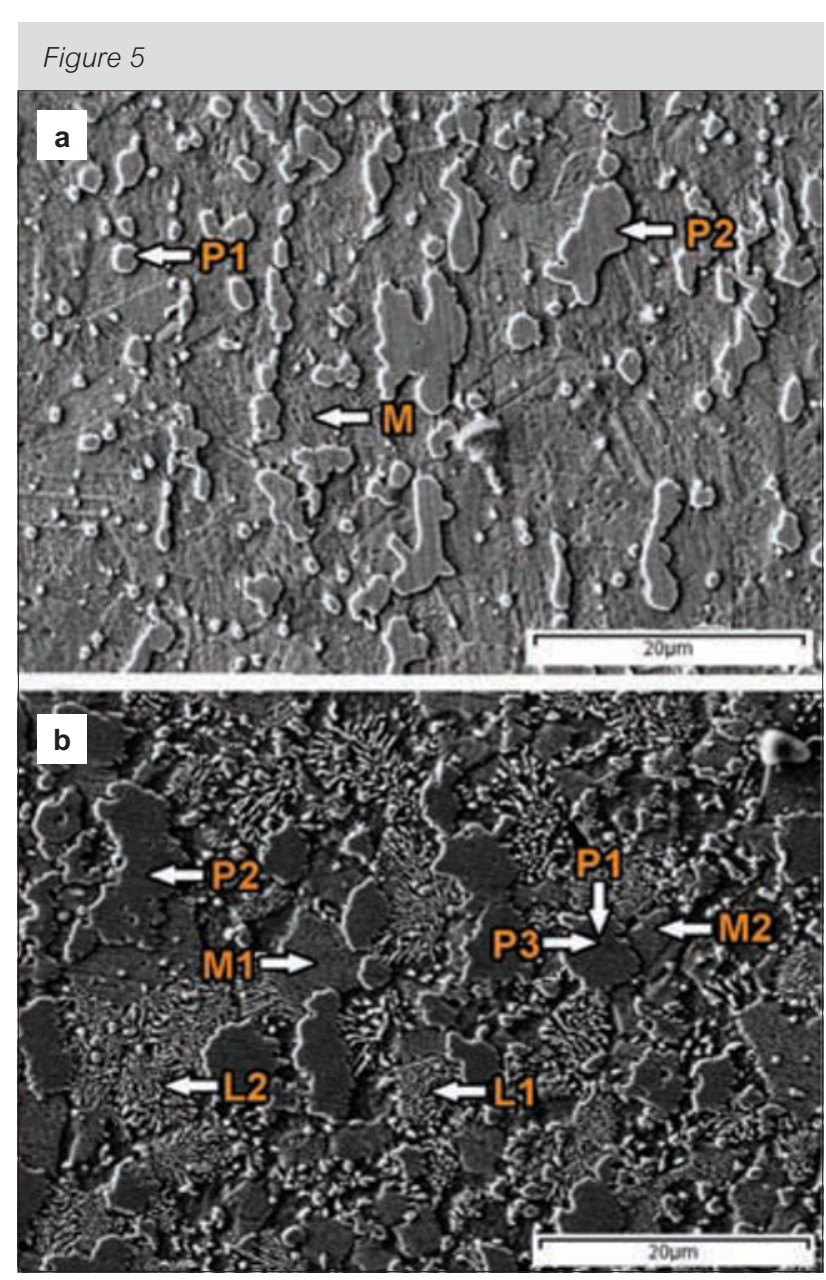

FE-SEM micrographs for the specimens solution-treated at $850^{\circ} \mathrm{C}$ for $15 \mathrm{~min}$ (a) and aged at $500^{\circ} \mathrm{C}$ for 20,000 $\mathrm{min}$ (b) 
Table 2.2: EDS analysis at the regions marked in Fig. 5-B for the specimen aged at $500^{\circ} \mathrm{C}$ for $20,000 \mathrm{~min}$

\begin{tabular}{|c|c|c|c|c|c|c|}
\hline Region (at\%) & $\mathrm{Au}$ & $\mathrm{Ag}$ & $\mathrm{Pt}$ & $\mathrm{Zn}$ & In & Pd \\
\hline M1 ( $\left.\alpha 1^{\prime}\right)$ & 52.7 & 37.7 & 0.4 & 0.8 & 5.1 & 3.3 \\
\hline M2 ( $\left.\alpha 1^{\prime}\right)$ & 51.7 & 36.1 & 1.6 & 0 & 6.0 & 4.6 \\
\hline P1 ( $\left.\alpha 2^{\prime}\right)$ & 27.6 & 3.5 & 29.0 & 3.3 & 21.8 & 14.8 \\
\hline P2 ( $\left.\alpha 2^{\prime}\right)$ & 27.2 & 6.2 & 28.7 & 2.8 & 21.0 & 14.1 \\
\hline P3 $(\alpha 3)$ & 17.3 & 4.3 & 32.4 & 27.3 & 10.4 & 8.3 \\
\hline L1 ( $\left.\alpha 1^{\prime}\right)$ & 49.3 & 37.6 & 2.1 & 4.0 & 3.1 & 3.9 \\
\hline L2 $(\beta)$ & 24.8 & 7.7 & 25.3 & 20.3 & 9.7 & 12.2 \\
\hline
\end{tabular}

of Fig. 5-A and Table 2-1, an increase in Au and Ag, and a decrease in Pt was detected compared to the base composition of Table 1. In the small and large particle-like structures $(P)$ of Fig. 5-A, the content of $\mathrm{Au}$ and $\mathrm{Ag}$ decreased, and that of $\mathrm{Pt}, \mathrm{Zn}, \mathrm{In}, \mathrm{Pd}$ increased apparently. The amount of $\mathrm{In}$ and $\mathrm{Zn}$ in $(P)$ regions was almost equal. From the above, it was clear that the Au-Ag-rich $\alpha_{1}$ phase composed the matrix and the $\alpha_{2}$ phase being Pt-Au-rich composed the particle-like structures. The minor $\alpha_{3}$ phase being Pt-Zn-rich was not detected due to the limited distribution.

In the over aged specimen (Fig. 5-B, Table 2.2), the matrix was Pt-, Zn-depleted $\alpha_{1}^{\prime}$ phase, in which the content of In increased slightly compared to that in the solution-treated specimen $(\mathrm{M} 1,2)$. In the FESEM micrograph, the matrix that was not replaced by the lamellar structure was covered by fine, dotlike structures. Thus, the increase of In indicated that the In-concentrated phase precipitated out from the solute-saturated grain-interior to form the fine, dot-like structures covering the matrix, even though the amount was not enough to be detected in the XRD peaks. Such a result can be expected from the Au-In binary phase diagram showing the decreasing miscibility of $\mathrm{In}$, in the Au-rich phase with decreasing aging temperature [1].

In the lamellar structure, an Au-Ag-rich layer (L1) and a Pt-Zn-rich layer (L2) were observed. It is possible that the elemental content detected in each layer of the lamellar structure contained elements of the neighboring layer to an extent, due to its fine nature. However, by considering the EDS results together with the obtained lattice parameter and the alloy composition, the lamellar structure was composed of the alternating Au-Ag-rich $\alpha_{1}^{\prime}$ and PtZn $\beta$ layers.
In dental Au-Ag-Cu alloys forming lamellar structure, a distributional inequality of $\mathrm{Au}$ is unusual in each layer of lamellar structure; because $\mathrm{Ag}$ and $\mathrm{Cu}$ have limited miscibility, while Au is completely soluble with both $\mathrm{Ag}$ and $\mathrm{Cu}[1,18,19]$. In the present study with $\mathrm{Au}-\mathrm{Ag}-\mathrm{Pt}$ alloy, the content of $\mathrm{Au}$, together with $\mathrm{Ag}$, was unequal in each layer of the lamellar structure, which was resulted from decreasing miscibility with decreasing aging temperature in Au-Pt and Ag-Pt systems $[1,20]$.

The composition of the particle-like structures changed apparently at $20,000 \mathrm{~min}$. In the $\mathrm{P}(1,2)$ regions of Fig. 5-B, the content of In increased and that of $\mathrm{Zn}$ decreased apparently compared to that in the $\alpha_{2}$ phase at $P$ regions of Fig. 5-A. By considering the $X R D$ results together, it can be concluded that the $\alpha_{2}$ phase being Pt-Au-rich containing equal amounts of $\mathrm{Zn}$ and In was transformed into the PtAu-rich $\alpha_{2}^{\prime}$ phase of In-increased and Zn-depleted. In the P3 region of Fig. 5-B, the Pt-Zn-rich $\alpha_{3}$ phase was detected, in which the contents of $\mathrm{Zn}$ were about three times of In. The minor $\alpha_{3}{ }^{\prime}$ phase was undetectable due to the limited distribution.

The EPMA analysis showed the same results as the EDS analysis. Fig. 6 shows the EPMA results of the specimen solution-treated at $850^{\circ} \mathrm{C}$ for $15 \mathrm{~min}(\mathrm{~A})$ and aged at $500^{\circ} \mathrm{C}$ for 20,000 min (B). It is clear in Fig. $6(\mathrm{~A})$ that the distribution of $\mathrm{Pt}, \mathrm{Pd}$ and $\mathrm{In}$ was contrast to that of $\mathrm{Ag}$ and $\mathrm{Au}$. In the particlelike structures, the $\mathrm{Zn}$-rich regions were almost overlapped with the $\mathrm{Pt}-\mathrm{Pd}$ - and In-rich regions. However, after aging a specimen at $500^{\circ} \mathrm{C}$ for 20,000 min (B), the overlapped regions of $\mathrm{Zn}$ with $\mathrm{Pt}-, \mathrm{Pd}-$ and In-rich regions had decreased apparently in the particle-like structures.

The XRD results showed that the $\alpha_{2}$ peak shifted toward a lower diffraction angle, as the $\alpha_{3}$ peak shifted toward a higher diffraction angle. Considering the above EDS results together with the XRD pattern changes, $\mathrm{Zn}$ that has a relatively small atomic size diffused out from the $\alpha_{2}$ phase to the $\alpha_{3}$ phase, and In that has a relatively large atomic size diffused out from the $\alpha_{3}$ phase to the $\alpha_{2}$ phase in the particlelike structures [21]. The In-Zn binary phase diagram shows the eutectic, which indicated that repulsive force works between In and Zn [1]. From the above, it can be concluded that the Pt-rich particle-like structures were composed of the major Pt-Au-rich $\alpha_{2}$ regions containing equal amounts of $\mathrm{Zn}$ and $\mathrm{In}$ and the minor Pt-Zn-rich $\alpha_{3}$ regions in which the contents of $\mathrm{Zn}$ were about three times of $\mathrm{In}$, and where the 


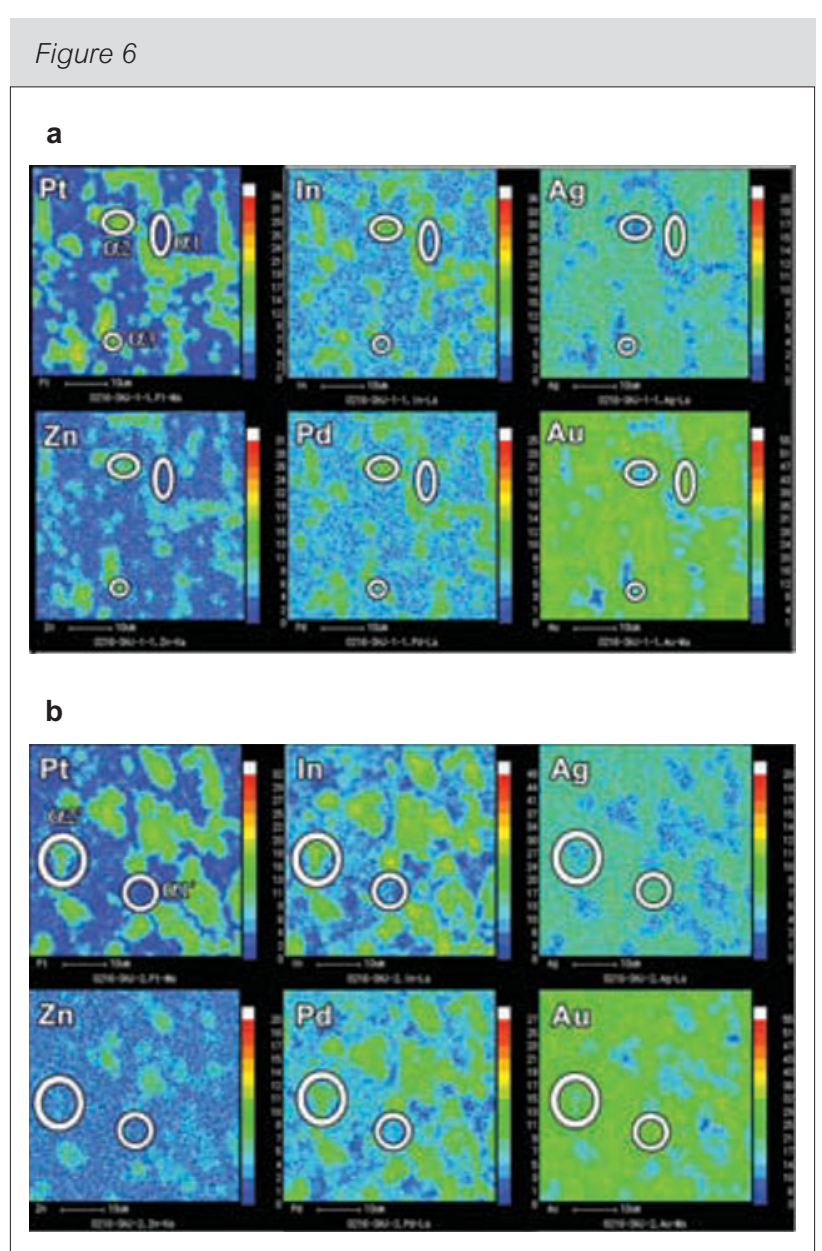

EPMA results of the specimen solution-treated at $850^{\circ} \mathrm{C}$ for 15 $\min \left(\right.$ a) and aged at $500^{\circ} \mathrm{C}$ for $20,000 \mathrm{~min}$ (b)

separation of In and Zn progressed with aging time without apparent microstructural changes. In the study with an Au-Ag-Cu-Pt-In alloy, the Au-containing $\mathrm{Pt}_{3}$ In particle-like structure was transformed into the Au-depleted particle-like structure containing relatively large amounts of $\mathrm{Cu}$ that was diffused from the Au-Ag-rich matrix, and which resulted from the overlapped miscibility limit of both Au-Pt and Ag-Cu systems [20]. However, in the present study with an Au-Ag-Pt-Zn-In alloy, such an Au-depletion in the Ptrich particle-like structure was not observed after transformation, as can be seen in Table 2(1,2). From such a fact, it was supposed that the separation of $\mathrm{In}$ and $\mathrm{Zn}$ occurred preferentially, suppressing the separation of Au out of the Pt-rich particle-like structure due to the large degree of immiscibility in the In-Zn system.

\section{Conclusions}

This study examined the complex precipitation mechanisms which are related to age-hardening in a dental Au-Ag-Pt-Zn-In alloy for multipurpose dental use, and the conclusions are as follows.

1. The optimum heat treatment for the Au-Ag-Pt-ZnIn alloy was achieved by aging at $500^{\circ} \mathrm{C}$ for $50 \mathrm{~min}$ after solution-treatment at $850^{\circ} \mathrm{C}$ for $15 \mathrm{~min}$.

2. The Au-Ag-rich $\alpha_{1}$ matrix was transformed into the Au-Ag-rich $\alpha_{1}^{\prime}$ matrix with aging time by precipitating the In-concentrated phase in the grain interior and the PtZn $\beta$ phase in the grain boundary, resulting in the hardening process.

3. The softening occurred as the Au-Ag-rich $\alpha_{1}{ }_{1}$ and PtZn $\beta$ lamellar-forming grain boundary reaction progressed. Both the volume fraction of lamellar structure and the inter-lamellar spacing were proportional to the decreasing rate in hardness.

4. In the particle-like structures composed of the major Pt-Au-rich $\alpha_{2}$ phase and the minor Pt-Zn-rich $\alpha_{3}$ phase, the separation of In and Zn progressed producing the In-increased Pt-Au-rich $\alpha_{2}^{\prime}$ phase and the $Z n$-increased PtZn $\alpha_{3}^{\prime}$ phase with aging time without restraining the softening.

5. The miscibility limit by complex systems of Au$\mathrm{Pt}, \mathrm{Ag}-\mathrm{Pt}, \mathrm{Au}-\mathrm{In}$ and In-Zn resulted in the phase transformation and related microstructural changes.

\section{About the authors}

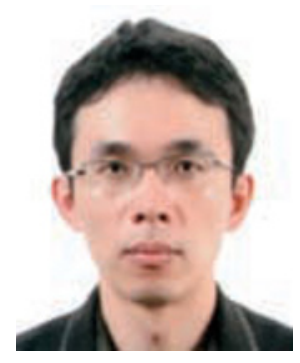

Joo-Hee Park Ph.D. is currently working on research of dental gold and alternative alloys at Pusan National University in South Korea.

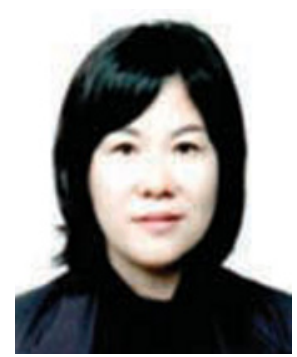

Mi-Hyang Cho Ph.D. is currently working on the research of dental gold alloy for ceramic-metal restorations at Pusan National University in South Korea. 


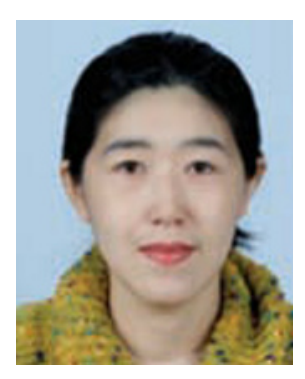

Mi-Gyoung Park Ph.D. is currently working on research of dental gold and alternative alloys at Catholic University of Pusan in South Korea.

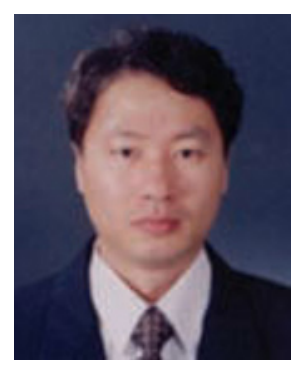

Yong Hoon Kwon is associate professor of Department of Dental Materials at Pusan National University in South Korea, Ph.D. in 1997.

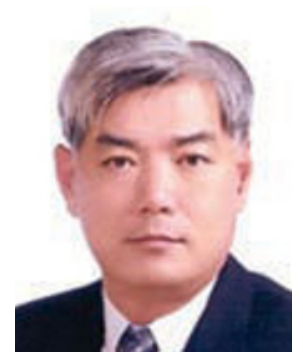

Hyung-Il Kim is chairman of

Department of Dental Materials at Pusan National University in South Korea, Ph.D. in 1989. On the editorial board of Dental Materials Journal (International Journal published by the Japanese Society for Dental Materials and Devices).

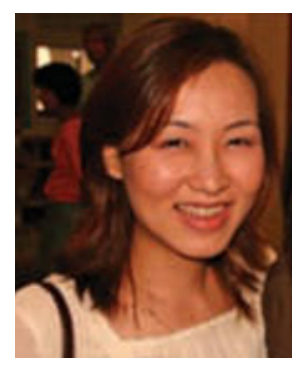

Hyo-Joung Seol* is assistant professor of Department of Dental Materials at Pusan National University in South Korea, Ph.D. in 2003. Her research focused on characterization of the agehardening mechanism of dental alloys.

\section{References}

1 T.B. Masslski, 'Binary alloy phase diagrams', second ed., ASM international, Materials Park, OH, 1990, pp. 12-13 (Au-Ag), 28-29 (Ag-Cu), 77-79 (Ag-Pt), 358-362 (Au-Cu), 381-383 (Au-In), 414-416 (Au-Pt), 2316-2319 (In-Zn)

2 K. Yasuda, M. Ohta, J. Less-Common Met., 1980, 70, 75

3 K. Yasuda, K. Udoh, K. Hisatsune, M. Ohta, Dent. Mater. J., 1983, 2, 48

4 T. Tani, K. Udoh, K. Yasuda, G. Van Tendeloo, J. Van Landuyt, J. Dent. Res., 1991, 70, 1350

5 H.I. Kim, M.I. Jang, B.J. Jeon, J. Mater. Sci.: Mater. Med., 1997, 8, 333

6 H.I. Kim, M.I. Jang, M.S. Kim, J. Oral Rehabil., 1999, 26, 215

7 D.L. Smith, A.P. Burnett, M.S. Brooks, D.H. Anthony, J. Dent. Res., 1970, 49, 283

8 R.A. Fuys, C.W. Fairhurst, W.J. O'Brien, J. Biomed. Mater. Res., 1973, 7, 471

9 K. Hisatsune, Y. Tanaka, T. Tani, K. Udoh, K. Yasuda, J. Mater. Sci.: Mater. Med., 1992, 3, 54

10 K. Hisatsune, Y. Tanaka, K. Udoh, K. Yasuda, J. Mater. Sci.: Mater. Med., 1997, 8, 277

11 P. Villars, L.D. Calvert, 'Pearson's handbook of crystallographic data for intermetallic phases', American Society for Metals, Metals Park, 1985, p. 3064

12 I. Kawashima, H. Ohno, N.K. Sarkar, Dent. Mater., 2000, 16, 75

13 H.J. Seol, T. Shiraishi, Y. Tanaka, E. Miura, K. Hisatsune, H.I. Kim, Biomaterials, 2002, 23, 4873

14 H. Winn, K. Udoh, Y. Tanaka, R.I. Hernandez, Y. Takuma, K. Hisatsune, Dent. Mater. J., 1999, 18, 218

15 H. Winn, Y. Tanaka, T. Shiraishi, K. Udoh, E. Miura, R.I. Hernandez, Y. Takuma, K. Hisatsune, J. Alloys Comp., 2000, 306, 262

16 H.K. Lee, H.M. Moon, H.J. Seol, J.E. Lee, H.I. Kim, Biomaterials, 2004, 25, 3869

17 K. Udoh, K. Hisatsune, K. Yasuda, M. Ohta, Dent. Mater. J., 1984, 3, 253

18 J.H. Lee, S.J. Yi, H.J. Seol, Y.H. Kwon, J.B. Lee, H.I. Kim, J. Alloys Compd., 2006, 425, 210

19 H.J. Seol, D.J. Noh, S.H. Lee, Y.H. Kwon, H.I. Kim, Mater. Charact., 2008, 59, 1190

20 H.J. Seol, J.H. Park, R.M. Ku, M.G. Park, Y.H. Kwon, H.I. Kim, Gold Bulletin, 2010, 43, 41

21 B.D. Cullity, 'Elements of X-Ray Diffraction', second ed., Addison-Wesley publishing Co Inc, Massachusetts, 1978, pp. 506-507 